\title{
XLV. On the alkalies of commerce, and on the least expensive process for ascertaining their commercial value by means of the instrument called the alkali-meter. Read to the Academy of rouen, 5 thermidor, An. 13, by M. Descroizilles senior
}

\section{Descroizilles}

To cite this article: M. Descroizilles (1807) XLV. On the alkalies of commerce, and on the least expensive process for ascertaining their commercial value by means of the instrument called the alkali-meter. Read to the Academy of rouen, 5 thermidor, An. 13, by M. Descroizilles senior, Philosophical Magazine Series 1, 28:112, 311-316, DOI: $10.1080 / 14786440708563525$

To link to this article: http://dx.doi.org/10.1080/14786440708563525

\section{Published online: 18 May 2009.}

\section{Submit your article to this journal $\longleftarrow$}

Џll Article views: 2 


\section{$\left[\begin{array}{ll}311 & ]\end{array}\right.$}

XLV. On the Alkalies of Commerce, and on the least expensive Process for ascertaining their commercial Value by Means of the Instrument called the Alkali-meter. Read to the Academy of Rouen, 5 Thermidor, An. 13, by M. Descroizilles senior.

[Concluded from p. 252.]

Necessity of a sufficient Proportion of Water, wilh supersaturated Carbonate of Potash, in order that the Potash may be completely disengaged ly Means of Lime.

IT must have been observed that, in the first article quoted in the preceding section, it has been prescribed to mix the potash with double its weight of lime, while in the second article no more than one-half is demanded; it is true, that less is required for the truly neutral carbonate of potash, because it contains a less quantity of alkali, and because the water of crystallization is here in greater proportion than in the supersaturated carbonate of potash ; but if we consider that the richest in alkali (being that which is obtained from cream of tartar) absorbs only 0.72 of its weight in sulphuric acid, while the quantity absorbed by the carbonate is 0.50 , we must admit that the proportions indicated in the two cases are no longer relative to each other.

On the other hand, rumernus experiments, made on a large scale, have constantly proved to me that four-tenths of lime are sufficient to take off the carbonic acid from the best potash of commerce; How happens it, therefore, that twenty tenths have been prescribed, aud still fears entertained that the potash was not perfectly caustic? I shall now show that this fear appears well founded, so long as the following observation of mine is unkuown: I have ascertained that, whatever be the proportion of the lime to the supersaturated carbonate of potash, if the proportion of water to this salt is not as seven to one, there will be a quantity of carbonate not decomposed, and proportionate to the deficit of water, in the seven parts which are strictly necessary. Besides, if we consult the tables of Bergman as to the re$\mathrm{U} 4$ spective 
spective quantities of carbonic acid which are found in the supersaturated carbonate of potash and in the carbonate of lime, we shall see that four-tenths of lime must be always sufficient for taking up all the carbonic acid contained in any given quantity of the best potash of commerce.

But here is a double experiment, which we may verify: Take of quicklime, 4 parts; of white potash of Russia, 10 parts; pure water, 70 parts : slake the lime with a portion of the water, and dissolve the potash in the remainder: afterwards mix the whole, boil it for a few minutes, then allow it to cool, and restore the whole of the 24 parts, which may have been diminished by the slaking of the lime and the ebullition; mix the added water very minutely; allow the whole to subside, and decant a little of the liquor: you will find, upon trying it, that no precipitate is formed in the lime water, and that it makes no efforescence with the acids.

In the second place, take the same proportions of lime and potash, but add only 50 parts of water to it; then try the liquor which will result from this, and you will find that it occasions a precipitate in lime water and an effervescence with the acids. Finally, add 20 additional parts of water to the first 50, and mix the whole carefully: the liquor, when decanted, will occasion neither precipitate nor effervescence : in a word, the alkali will have become caustic in consequence of the extraction of all its carbonic acid.

I am inclined to think that this observation may be usefully applied to the caustification of soda.

\section{Explanation of the Causes of the Uncertainty in the Pro- cesses of Caustification.}

We now see clearly the reason why we cannot obtain a perfectly caustic alkali, if we do not add a sufficient quantity of water to the mixture of lime and supersaturated carbonate of potash. Although it might be thought we have used too much lime already, yet we must put still more into the mixture; but as it might become too thick, we are under the necessity of adding a new portion of water, which alone completes the caustification, although this has been, nevertheless, attributed to the new addition of lime. 
Lastly, we see the reason why from a mixture of lime and of supersaturated carbonate of potssh, with too little water, the first lixivium, which may be filtered, will be effervescent, while that which may be obtained from washings, i.e. by the addition of a new quantity of water, will come off entirely caustic.

These alternatives might take place upon the execution of the second of the processes, already quoted, of M. Fourcroy, because the proportion of water is then indeterminate; while in the first process, if it be equal to eight or ten times the total weight of the supersaturated carbonate of potash and lime, it is evident that we ought consequently to obtain potash totally deprived of carbonic acid, if we have never, by the ebullition prescribed of two or three hours, reduced the proportion of water to a less quantity than seven times the weight of the supersaturated carbonate of potash : for my own part, I am convinced that an ebullition of a few minutes is at all times sufficient.

\section{Potash exists in all Lime which is burnt by a Wood Fire.}

I shall now proceed to announce some facts connected with the preceding observations.

So long ago as the year 1795 , my brother and I obserred that lime, when burnt by means of wood, contained potash : this will not appear surprising when we consider the great lightness of some particles of ashes, which may be called flowers of ashes: there is no wood fire, let it be ever so small or moderate, that does not emit these flowers, and we see them attached to the kitchen utensils which are heated upon a wood fire. Their alkaline property will be evident if we first moisten the tip of the finger with a little saliva, and afterwards lay it gently upon the vessels to which these flowers are attached. On afterwards applying the finger to the tongue, a very decided alkaline taste will be perceived. It may be easily conceived, therefore, that in a violent fire, such as that of a lime-kiln, the current of air which traverses it carries these light ashes through the pieces of calcareous stones. The earthy part of these ashes stops at the exterior 
of the pieces of limestone, which contract a colour more or less gray; while the potash going really into vapours, from the violence of the fire, passes into the interior of the stone, which, after being burnt, remains very white. We carefully detached and analysed a great quantity of this external matter, and we there found the exact proportion of potash which existed in the whole mass of the pieces : this proportion was nearly a 5-100dth of the weight of the lime.

Chemists who may repeat our experiments will find in lime more or less potash than the quantity above announced; it must vary according to circumstances, and particularly from the nature of the wood employed in burning the lime.

Some chemical Anomalies clearly explained by the Presence of Potash in Lime, and the Necessity of previously washing the Lime, or of employing, in chemical Experiments and medical Preparations, Lime lurnt with Pit Coal.

By this means we may consequently explain the pretended decomposition of a very small quantity of muriate of soda operated by a very great quantity of lime; an error into which the immortal Scheele has fallen, and in which he has been followed by some of our most celebrated French chemists *.

Some chemists have also been led into error upon mixing sulphate of soda and lime.

This also explains the disputes among the chemists of the Academy of Sciences (and which are contained in the memoirs of that learned body about the commencement of the last century) upon a salt which some of them said was found in lime, while others denied its existence entirely.

Thence proceeds the well-founded idea of a property peculiar to the first water drawn off lime; a property which has been improperly contested, and which cannot exist in second lime water.

* I do not mean, however, to deny that in some particular cases lime can decompose the muriate and the sulphate of soda; I merely insist that we may be allowed to doubt it, provided we are not previously certain that the lime mixed with the one or other of these salts did not contain potash. 
This is the reason why some sugar-refiners take great pains, and expend a great deal of money, for a first lime water, which they might obtain by a little potash and lime.

Lime water is recommended by some oculists : it is for them to consider whether it is proper that it should contain caustic potash, i.e. the caustic stune. This observation is equally applicable to the internal use of lime water, prescribed by some physicians.

In chemical experiments, therefore, such as making the precipitate and sulphuret of lime, \&c., we nust employ lime burnt with coal, or it must be washed if it has been burnt with wood.

\section{Origin of Natural Soda, as it is called.}

The efflorescences of carbonate of soda, found under the arches of the Pont-neuf, at Paris; those of the cellars at Dieppe and other maritime places, are no longer objects of astonishment. A few years ago, when at Dieppe, I had occasion to ascertain the origin of these efflorescences mixed with sulphate of soda. I descended into the cellar, under the kitchen, of my paternal residence, where in my infancy I had seen the linen of a numerous family washed. The arch of this cellar had been formerly plastered. The greatest part of this plaster was now detached; but where it still remained there was sulphate of soda, while beside it there was only carbonate of soda. The origin of these two salts was no longer a mystery to me; for, independently of the potash existing in the lime of the vault, the leys, when the linen was washed, had penetrated the masonry; they had there met with kitchen salt, which had been consequently decomposed; hence the carbonate of soda. This last, wherever it found sulphate of lime, had given place to the formation of sulphate of soda.

It often requires but a slight degree of reflection, upon all the circumstances which accompany results most extraordinary in appearance, in order to explain the most striking contrasts ; and for this purpose a great number of facts, hitherto ill explained, must be reviewed. 
First Indication of the Mineralogical Inquiries necessary to. be made as to the Existence of Potash.

In an essay upon the art of making saltpetre, which I presented to the National Institute several years ago, I explained the origin of what is called natural soda, and I took that occasion to inquire what became of the potash confined in the lowels of the earth. About a year afterwards M. Klaproth discovered it in several volcanic productions; and his discovery was soon confirmed by M. Vauquelin. It is peculiarly gratifying to me to have suggested the idea of these useful researches.

\section{Proballe Origin of Natrum.}

I am strongly inclined to think that the natrum of the lakes in Egypt and other places owes its origin to the decomposition of the muriate of soda by potash, which is one of the products of the disorganization of vegetables; for the shores of the six lakes of Egypt, and the adjacent soils, are covered with jonquils and roses, which must annually furnish plenty of potash. It would be easy to verify this explanation by experiments, which promise more success than those which have been made with other views. To conclude: the explanation which I thus gave, previous to the late memorable travels of several of our learned men in Egypt, before it be confirmed, would require us to prove the coexistence of the muriate of potash along with the other salts, in the lakes of natrum and in the waters of the Nile.

XLVI. Report of the Royal College of Physicians of London on Vaccination. Printed by Order of the House of Commons, dated 8th July 1807 .

$T_{\text {he Royal College of Physicians of London, having re- }}$ ceived his majesty's commands, in compliance with an address from the house of commons " to inquire into the state of vaccine inoculation in the united kingdom, to report their opinion 